\title{
Desain Majalah Sebagai Media Company Profile Pada PT. Uman Surya Alam
}

\author{
Wendy Andriyan ${ }^{1}$, Farahdina Agustine ${ }^{2}$, Diah Lilis Relawati ${ }^{* 3}$ \\ ${ }^{1,2,3}$ Program Studi Teknik Informatika, Fakultas Sains and Teknologi, Universitas \\ Raharja Email: ${ }^{1}$ wendy@ raharja.info, ${ }^{2}$ farahdina.agustine@ raharja.info, \\ "3iah.lilis@ raharja.info
}

\begin{abstract}
Abstrak
Company Profile adalah identitas bagi perusahaan agar dapat dikenal lebih luas mengenai sejarah, tujuan dan produk yang ditawarkan. Banyaknya perusahaan saat ini, telah berlomba-lomba membuat media company profile untuk memperkenalkan identitasnya dan juga sebagai pencitraan untuk meningkatkan image perusahaan dalam memenangkan persaingan memperebutkan customer. Salah satu media company profile yang memberikan pengaruh besar bagi perusahaan adalah desain majalah, dimana di dalamnya terdapat teks, gambar dan tampilan visual yang menarik dalam mendukung penyampaian informasi secara lengkap sesuai dengan yang ingin ditampilkan pada media desain majalah. Sebagai perusahaan yang bergerak di bidang job service/repair performed, Media informasi yang ada sebelumnya dinilai kurang dalam penyampaiannya, karena disajikan dalam bentuk website yang memiliki tampilan visual kurang menarik dan kurang terstruktur dalam penataan informasinya, sehingga akan mengurangi brand image produk atau perusahaan. Maka dari itu PT Uman Surya Alam memerlukan media promosi dan informasi berupa desain majalah sebagai company profile yang dapat menyampaikan informasi secara lengkap dengan tampilan visual yang menarik, clean dan elegan. Metode yang digunakan pada penelitian ini yaitu metode penelitian lapangan (field research) untuk mengumpulkan data dengan cara observasi, wawancara dan studi pustaka lalu menggunakan metode analisa kualitatif untuk menyederhanakan data yang sudah ada. Penelitian ini menghasilkan sebuah desain majalah company profile yang dibuat menggunakan software Adobe Illustrator CC 2015 agar lebih efektif dalam memperkenalkan brand image produk atau perusahaan dan efesien dalam menjelaskan tentang perusahaan.
\end{abstract}

Kata Kunci-Company Profile, Media Promosi, Media Informasi, Desain Majalah.

\begin{abstract}
Company Profile is an identity for the company so that it can be known more widely about the history, goals and products offered. Many companies today, have been competing to create a media company profile to introduce their identity and also as an image to improve the company's image in winning the competition for customers. One of the company profile media that has a big influence on the company is magazine design, which includes text, images and attractive visuals to support the delivery of complete information in accordance with what you want to display on the magazine design media. As a company engaged in job service/repair performed, the previously available information media is considered lacking in its delivery, because it is presented in the form of a website that has an unattractive visual appearance and is less structured in structuring the information, so that it will reduce the brand image of the product or company. Therefore PT Uman Surya Alam requires promotional media and information in the form of magazine design as a company profile that can convey complete information with an attractive, clean and elegant visual appearance. The method used in this study is a field research method to collect data by means of observation, interviews and literature study and then using qualitative analysis methods to simplify existing data. This study resulted in a company profile magazine design made using Adobe Illustrator CC 2015 software to be more effective in introducing the brand image of a product or
\end{abstract}


company and efficient in explaining about the company.

Keywords - Company Profile, Promotion Media, Information Media, Magazine Design.

\section{PENDAHULUAN}

Company Profile merupakan media informasi dan promosi yang digunakan untuk menyampaikan sebuah nilai positif untuk suatu perusahaan ${ }^{[1]}$. Isi pesan company profile adalah pemaparan nilai lebih (corporate value) dan nilai lebih produk (product value) yang akan disampaikan. Pada sisi yang lain, perusahaan juga perlu untuk menyampaikan apa produk yang dihasilkannya dan manfaat produk tersebut bagi calon konsumen ${ }^{[2]}$. Penyampaian informasi tersebut tentunya membutuhkan sebuah media yang dapat mencakup informasiinformasi penting yang dibutuhkan dalam company profile, seperti sejarah tumbuhnya perusahaan, kepercayaan dan reputasi yang diberikan oleh customer, serta produk yang disediakan dan ditawarkan untuk melayani kebutuhan customer. Salah satu media yang dapat digunakan untuk membuat company profile adalah media desain. Desain adalah suatu cara untuk merancang sesuatu yang sebelumnya sudah direncanakan mengenai struktur dan bentuk yang akan dibuat. Setelah rancangannya telah diperoleh, maka langkah selanjutnya adalah melakukan implementasi ${ }^{[3]}$. Kita dapat mendesain suatu media berdasarkan kebutuhan dari informasi yang ingin disampaikan secara detail dan menarik, seperti media desain majalah. Majalah merupakan salah satu media yang berisi informasi-informasi yang memiliki kelebihan yaitu menampilkan teks yang bervariasi disertai gambar-gambar yang dipadukan dengan warna menarik sehingga mampu menarik minat banyak orang untuk membacanya ${ }^{[4]}$.

Dalam hal ini, salah satu perusahaan yang membutuhkan media desain, khususnya desain majalah adalah PT. Uman Surya Alam yang bergerak di bidang job service/repair performed dan beralamat di JL.Raya Curug KM 2,5 Kadu Jaya Kec. Curug Kab. Tangerang. PT Uman Surya Alam merupakan perusahaan lokal asli Indonesia yang memiliki standar kualitas internasional, bersertifikat; ISO 9001-2015 QHS; ISO 14001, keanggotaan EASA (Electrical Apparatus Service Association), memiliki tenaga kerja terdidik dan berpengalaman dan memiliki 10 sampai 20 tahun pengalaman di perusahaan Multinasional. Sebagai perusahaan yang menyediakan layanan job service/repair performed seperti rotating machine service, condition base monitoring, vibration analysis \& troubleshooting, alignment/set up of machine, onsite balancing with portable dual channel balancer, mechanical repair work such as shaft replacement, sleeve Bearing rebabbit, dan spare parts supply for motor/generator, tentunya membutuhkan media company profile yang dapat memberikan gambaran secara jelas mengenai informasi perusahaan maupun produk yang ditawarkan untuk diperlihatkan ke konsumen. Dengan begitu, konsumen dapat mengetahui secara detail tentang perusahaan berdasarkan informasi yang ada pada media desain majalah yang telah dibuat semenarik mungkin. Terlebih saat ini, PT Uman Surya Alam belum memiliki media company profile yang dapat diperlihatkan ke calon konsumen maupun masyarakat luas tentang perusahaan. Berdasarkan permasalahan diatas, penulis berinisiatif membuat media yang dapat menjadi wadah informasi bagi PT Uman Surya Alam sekaligus menciptakan daya tarik yang kuat dalam bentuk desain majalah yang dikemas semenarik mungkin dengan komposisi layout clean, minimalis dan elegan.

\section{METODE PENELITIAN}

Ada beberapa metode yang digunakan oleh penulis untuk mendapatkan dan melengkapi data yang dibutuhkan dalam menyelesaikan penelitian ini, diantaranya ada (1) Metode pengumpulan data melalui tahapan (a) Observasi, yaitu metode penelitian yang digunakan oleh penulis untuk mendapatkan data dan informasi secara langsung dengan mendatangi PT Uman Surya Alam, selaku perusahaan yang dijadikan tempat penelitian. (b) Wawancara, yaitu metode yang digunakan oleh penulis dengan cara melakukan komunikasi 
secara langsung berupa tanya jawab yang dilakukan kepada pihak perusahaan, untuk mendapatkan informasi yang digunakan sebagai kelengkapan data dalam penelitian ini. (c) Studi Pustaka, yaitu metode yang digunakan untuk mengumpulkan informasi dengan cara mempelajari dan menganalisa materi, buku atau karya ilmiah yang sudah ada dan memiliki keterkaitan informasi mengenai penelitian yang dilakukan oleh penulis. Selanjutnya (2) Metode analisa yang digunakan dalam penelitian ini adalah metode kualitatif, yaitu mengumpulkan seluruh data yang telah di dapatkan pada tahap pengumpulan data seperti observasi, wawancara dan studi pustaka. Setelah itu, data diperiksa kembali dan penulis melakukan rangkuman terhadap hal-hal yang dianggap penting, mencari pola dan alurnya seperti apa dan tidak menuliskan hal-hal yang tidak perlu. Hal ini bertujuan untuk menyederhanakan data yang diperoleh selama penelitian berlangsung di tempat penelitian. Setelah data disederhanakan, selanjutnya data yang sudah ada disajikan dalam sekumpulan informasi yang dibentuk dalam format tersusun dengan baik dan pada tahap akhir, mencari kesimpulan dan verifikasi dari data yang sudah ada.

\section{Literature Review}

Penelitian yang dilakukan oleh Putri dan Radja Erlan Hamzah pada tahun 2018 ${ }^{[6]}$, dengan judul "Konvergensi Konten Majalah Popular Dalam Industri Digital Media Cetak." Penelitian ini membahas tentang menunjukan majalah popular menempuh model konvergensi content dan tampil di berbagai platform sosial dengan satu tujuan, yaitu untuk mempertahankan eksistensi keberadaan majalah popular dalam industri media masa. Metode yang digunakan pada penelitian ini yaitu menggunakan deskriptif kualitatif, dianalisis secara kualitatif, menggunakan purposive sampling untuk pengambilan informan dan pengumpulan data dengan wawancara, dokumentasi dan studi pustaka. Perbedaan dari penelitian ini terletak pada hasilnya yaitu hanya sebatas konvergensi content pada media majalah dan hanya berbentuk riset.

Penelitian yang dilakukan oleh Maulani, dkk pada tahun $2017^{[7]}$, dengan judul "Desain Media Komunikasi Visual Berbentuk Tabloid Sebagai Sarana Promosi SMK Mandiri 2." Penelitian ini membahas tentang pembuatan media promosi SMK Mandiri 2 menggunakan media desain yang mencakup informasi-informasi mengenai sekolah dan bertujuan untuk memperkenalkan ke masyarakat luas. Media desain yang dimaksud adalah media komunikasi visual seperti tabloid yang dinilai efektif karena dapat memberikan berbagai informasi serta meningkatkan citra SMK Mandiri 2 melalui informasi yang dijelaskan pada media tabloid karena dapat membuat sekolah semakin dikenal oleh masyarakat luas. Adapun metode yang digunakan pada penelitian ini adalah metode pengumpulan data, Metode analisis desain media, serta Metode konsep produksi media (KPM). Perbedaan dari penelitian ini adalah sasarannya, dimana perancangan desain ini ditujukan untuk kepentingan akademik sebagai bentuk promosi dalam menarik minat calon Siswa/Siswi.

Penelitian yang dilakukan oleh Widada, dkk pada tahun $2020^{[8]}$, dengan judul "Perancangan Media Promosi dan Informasi Berbentuk Desain Majalah Pada SMK Ki Hajar Dewantoro." Penelitian ini membahas tentang perancangan media promosi dan informasi dalam bentuk majalah menggunakan aplikasi Adobe Premiere Pro CC, Adobe Photoshop CC dan Adobe Illustrator $C C$, yang dapat dimanfaatkan untuk meningkatkan minat dan target produk dari SMK Ki Hajar Dewantoro. Penelitian ini menggunakan metode pengumpulan data seperti observasi, wawancara, dan studi pustaka yang di dukung dengan konsep produksi media (KPM) untuk melakukan produksi atau perancangan desain media promosi dan informasi majalah. Perbedaan dari penelitian ini adalah sasaran dan konsepnya, yaitu sebagai bentuk promosi untuk memperkenalkan sekolah ke masyarakat luas, khususnya untuk calon Siswa/Siswi baru agar tertarik untuk bergabung.

Penelitian yang dilakukan oleh Kusuma, dkk pada tahun $2020^{[9]}$, dengan judul "Desain Majalah Guna Media Penunjang Informasi Pada PT Pramesta Baja Utama." Penelitian ini membahas tentang pembuatan media penunjang informasi pada PT Pramesta Baja Utama berupa desain majalah yang dibuat menggunakan aplikasi adobe photoshop CS6 dan nantinya 
akan diperlihatkan ke calon customer agar tertarik dengan produk yang ditawarkan oleh PT Pramesta Baja Utama. Adapun metode yang digunakan pada penelitian ini yaitu metode pengumpulan data dengan cara mengunjungi lokasi yang bersangkutan dan kemudian mengeksekusinya dengan mendesain sebuah media informasi dan promosi majalah. Perbedaan dari penelitian ini adalah konsep desainnya yang lebih dominan berwarna merah dengan gambar kontruksi sebagai identitas desainnya.

Penelitian yang dilakukan oleh Apriani, dkk pada tahun $2020^{[10]}$, dengan judul "Desain Majalah Berbentuk Informasi Dan Promosi Pada PT Prabayksa Surya Albantani Kabupaten Tangerang." Penelitian ini membahas pembuatan media cetak majalah yang bertujuan untuk menginformasikan dan mempromosikan PT Prabayaksa Surya Albatani Kabupaten Tangerang yang menjelaskan tentang perusahaan, baik itu sejarah, visi dan misi serta produk yang ditawarkan. Hal ini bertujuan agar PT Prabayaksa Surya Albatani Kabupaten Tangerang dapat dikenal lebih luas oleh masyarakat, sehingga dapat meningkatkan citra perusahaan dan daya tarik calon customer. Desain majalah yang dibuat menggunakan software desain seperti adobe photoshop CS6 dan menggunakan metode pengumpulan data dengan mendatangi tempat penelitian secara langsung. Perbedaan dari penelitian ini adalah sasaran dan konsepnya, yaitu untuk mempromosikan dibidang travel Umroh dan Haji, dengan konsep desain berwarna hitam gelap dengan perpaduan teks berwarna putih.

\section{HASIL DAN PEMBAHASAN}

\subsection{Konsep Perancangan}

Perancangan desain majalah company profile ini memiliki beberapa konsep perancangan, yaitu:

\section{Perancangan Media}

Sebagai bentuk dukungan terhadap strategi pemasaran pada PT Uman Surya Alam agar masyarakat luas khususnya calon konsumen dapat mengetahui identitas perusahaan dan layanan seperti apa yang ditawarkan, maka perancangan desain majalah yang dibuat nantinya berisi informasi yang berkaitan dengan kepentingan company profile. Adapun desain majalah company profile ini terdiri dari beberapa bagian yang disusun menjadi satu kesatuan informasi, yang dirancang semenarik mungkin dan di dalamnya terdapat unsur visual yang memberikan kesan perusahaan, mulai dari menambahkan logo, penyesuaian warna agar terlihat menarik secara visual, pemilihan typography yang ramah untuk dilihat serta penyesuaian layout majalah terhadap informasi-informasi yang ditampilkan di dalamnya guna mewakili identitas perusahaan. Berikut adalah daftar desain yang dibuat oleh penulis:
1. Desain Cover
2. Desain Backcover
3. Desain About Company
4. Desain Legal Document
5. Desain Company Address
6. Desain Vision and Mission
7. Desain History Company
8. Desain Majalah Workshop Equipment
9. Desain Majalah Mechanical T\&M Equipment
10. Desain Majalah Licence
11. Desain Majalah Our Customer

\section{Perencanaan Pesan (Konsep Kreatif)}

Perencanaan pesan pada desain majalah company profile ini memperhatikan pesan 
yang ingin dikomunikasikan melalui tujuan kreatif dan strategi kreatif, dimana media desain majalah ini bertujuan untuk memperkenalkan identitas perusahaan, menanamkan persepsi yang baik tentang perusahaan dan membangun awareness tentang kualitas kerja, hasil yang baik dan kelengkapan peralatan yang dimiliki oleh PT Uman Surya Alam sebagai perusahaan yang bergerak dibidang perbaikan dan perawatan mesin. Desain majalah yang dibuat menggabungkan unsur-unsur penting seperti teks, gambar dan warna dalam mencapai strategi kreatif untuk menghasilkan tampilan yang kreatif dan memiliki kesan modern.

\section{Perencanaan Visual}

Tampilan visual yang ingin diperlihatkan ke dalam media desain majalah ini adalah pembentukan layout desain yang memiliki kesan simple dan clean agar ramah terhadap pengelihatan. Penyajian informasi pada majalah ditempatkan secara terstruktur mulai dari halaman pertama hingga halaman terakhir yang di dalamnya terdapat teks sebagai deskripsi dan beberapa informasi perusahaan dalam bentuk gambar, sehingga penyampaian informasi lebih tertarget dan terarah. Warna desain yang dipilih telah menggambarkan tentang identitas perusahaan sekaligus menjadi warna yang disarankan oleh pihak perusahaan, yaitu warna biru. Dimana warna biru tersebut juga digunakan pada logo perusahaan, sehingga memiliki keterikatan. Pada bagian typography, bentuk yang dipilih disesuaikan dengan kenyamanan membaca serta di dukung dengan warna yang telah disesuaikan dengan warna desain.

\section{Skema Alur Kerja}

Dalam proses pembuatan desain majalah yang akan digunakan sebagai media company profile pada PT Uman Surya Alam, terdapat skema alur kerja berikut ini untuk

1. Melakukan Briefing mengenai penyusunan informasi seperti apa yang harus ada dan dibutuhkan pada desain majalah yang akan dibuat.

2. Menemukan ide desain majalah yang ingin dibuat mulai dari layout, warna, hingga penempatan unsur-unsur informasi penting sesuai dengan arahan yang diberikan pada saat melakukan Briefing.

3. Selanjutnya mulai menyusun, membentuk, dan menggabungkan unsur-unsur penting yang dibutuhkan hingga menghasilkan desain majalah yang diminta.

4. Setelah desain majalah selesai, lalu masuk ke proses penilaian untuk menentukan apakah hasil desain perlu direvisi atau sudah lebih dari cukup sesuai dengan yang diharapkan.

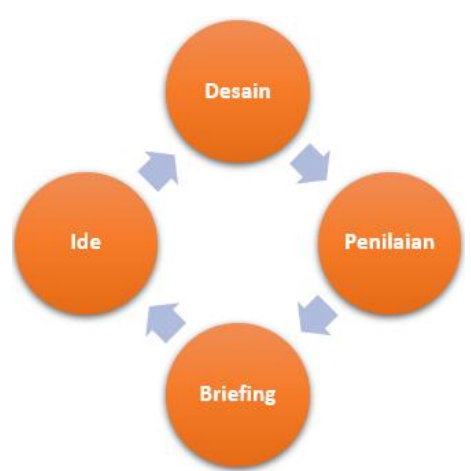

Gambar 1. Skema Alur Kerja 


\subsection{Pengarahan Visualisasi}

Tonalitas warna yang dipilih dalam desain majalah company profile ini adalah biru sebagai warna dominan, dikarenakan warna biru adalah identitas dari PT Uman Surya Alam, yang mana warna tersebut juga digunakan pada logo perusahaan. Adapun warna dukungan yang digunakan yaitu putih sebagai background untuk meletakan teks dengan warna hitam agar mudah terlihat dan sedikit warna Rodeo Dust (Kode hex: \#C1A580) pada salah satu bagian halaman untuk menyesuaikan dengan isi informasi yang ditampilkan. Jenis huruf yang dipakai pada majalah ini telah disesuaikan dengan bentuk layout yang digunakan dan juga tingkat kenyamanan saat dibaca, yaitu Stencil digunakan pada heading dan Impact digunakan pada deskripsi. Model yang digunakan dan ditampilkan pada desain majalah ini menggunakan landscape dengan ukuran A3 sebanyak 14 halaman termasuk dengan cover depan dan belakang.

\subsection{Strategi Media}

Strategi penggunaan media sebagai company profile ini dilakukan dengan cara mengimplementasikannya ke dalam media cetak dan juga dapat disebarluaskan dalam bentuk digital (E-Magazine) melalui website yang dimiliki oleh PT Uman Surya Alam. Majalah ini berisi hal-hal yang diunggulkan dan layanan yang disediakan oleh perusahaan dalam mempengaruhi daya tarik calon konsumen maupun konsumen yang sudah menggunakan jasa perbaikan mesin agar terus percaya terhadap kinerja perusahaan.

\subsection{Layout Kasar}

Layout kasar adalah tahap pertama dalam melakukan perancangan desain yang umumnya berbentuk seketsa untuk mendapatkan gambaran bentuk serta penempatan informasi-informasi yang cocok digunakan pada saat proses desain menggunakan aplikasi komputer. Sehingga hasilnya sesuai dengan bentuk yang telah diperlihatkan melalui layout kasar. Pada tahap ini, sketsa masih bisa dilakukan perubahan selama belum final dan belum masuk dalam proses pembuatan. Berikut adalah layout kasar yang telah dibuat:

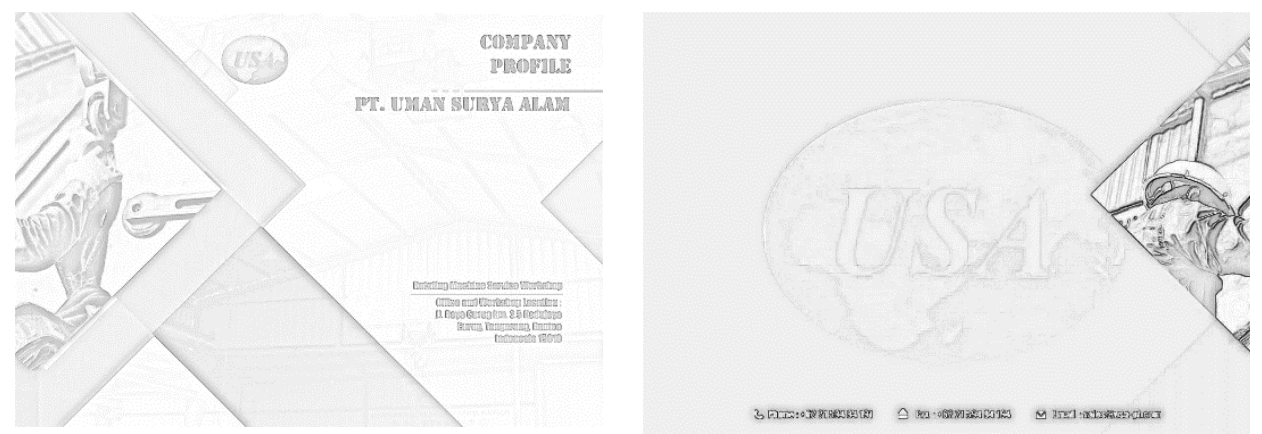

Gambar 2 dan 3. Layout Kasar Cover dan Backcover

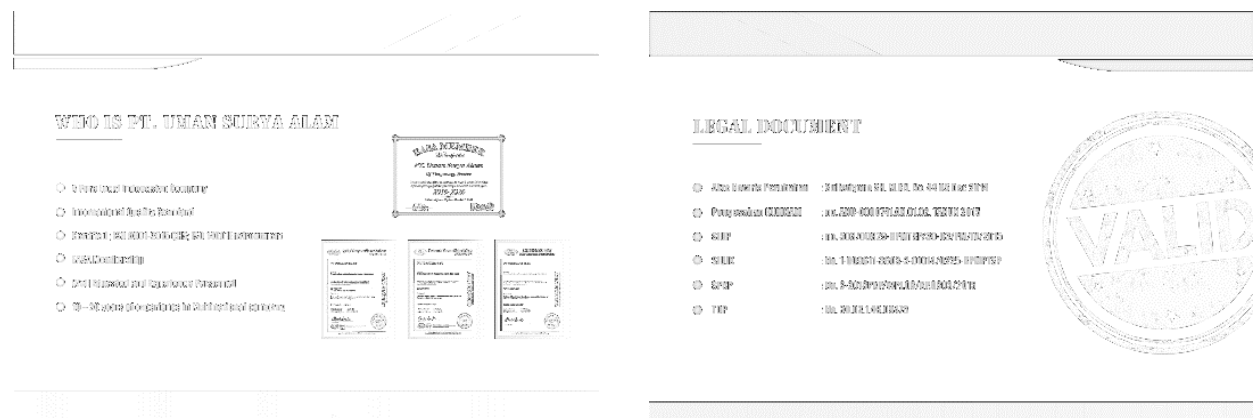

Gambar 4 dan 5. Layout Kasar About Company dan Legal Document 

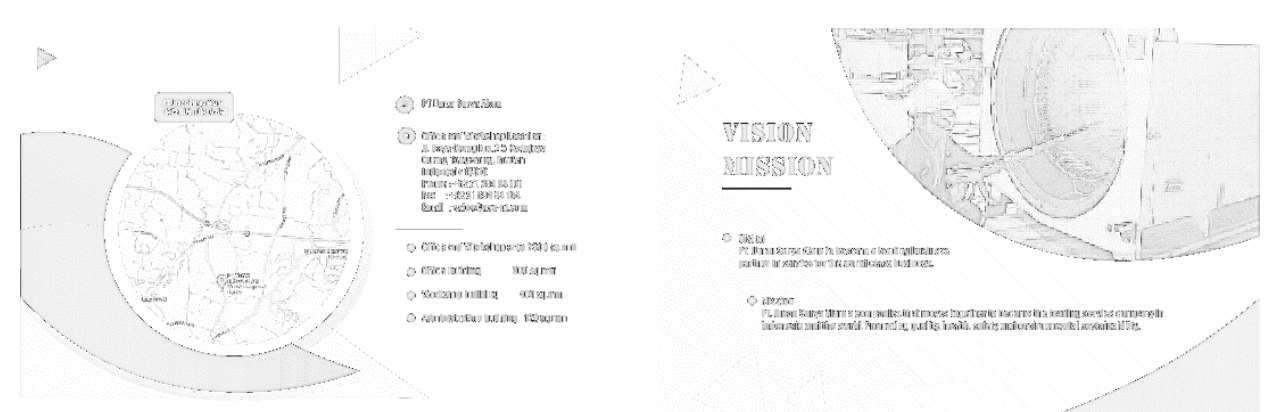

Gambar 6 dan 7. Layout Kasar Company Address dan Vision Mision
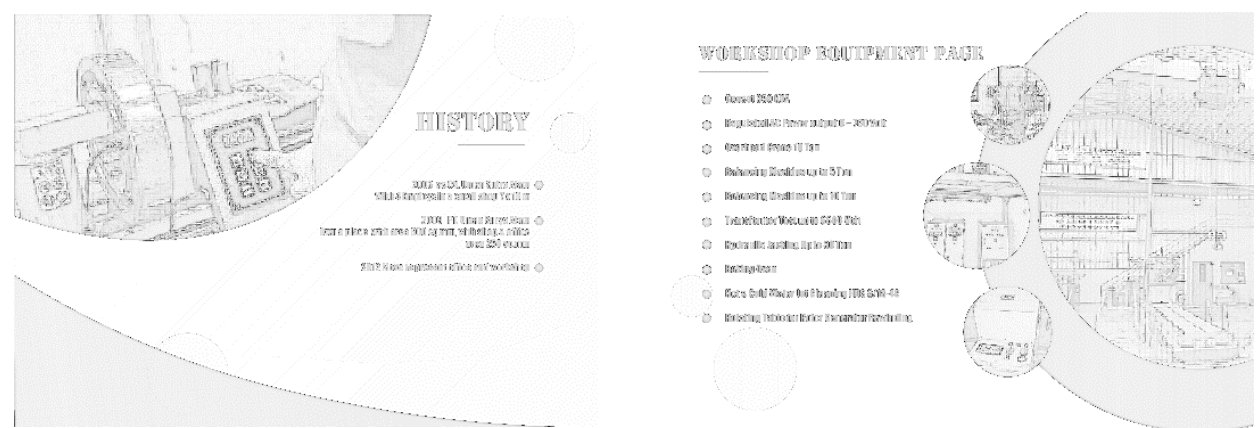

Gambar 8 dan 9. Layout Kasar Company History dan Workshop Equipment
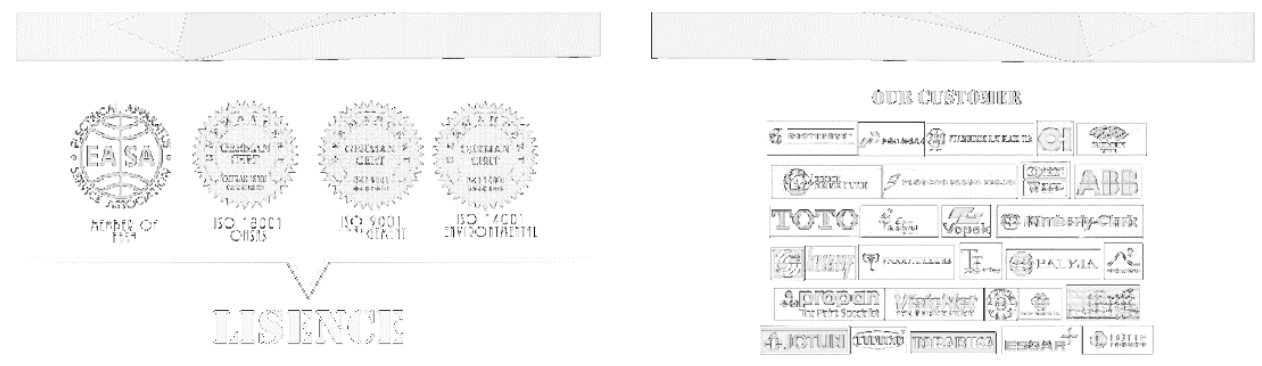

Gambar 10 dan 11. Layout Kasar License dan Our Customer

\subsection{Layout Komprehensif}

Layout komprehensif adalah tahap lanjutan setelah layout kasar. Setelah mendapatkan gambaran mengenai desain yang ingin dibuat, maka pada tahap ini proses pembuatan desain sudah memasuki tahap komputerisasi, mulai dari pembentukan hingga pewarnaan. Hasil desain yang terlihat sudah mendekati komposisi final namun masih harus melewati tahap revisi. Berikut merupakan layout komprehensif pada desain majalah company profile ini: 
Print ISSN: 2723-1992

Online ISSN: 2723-200X
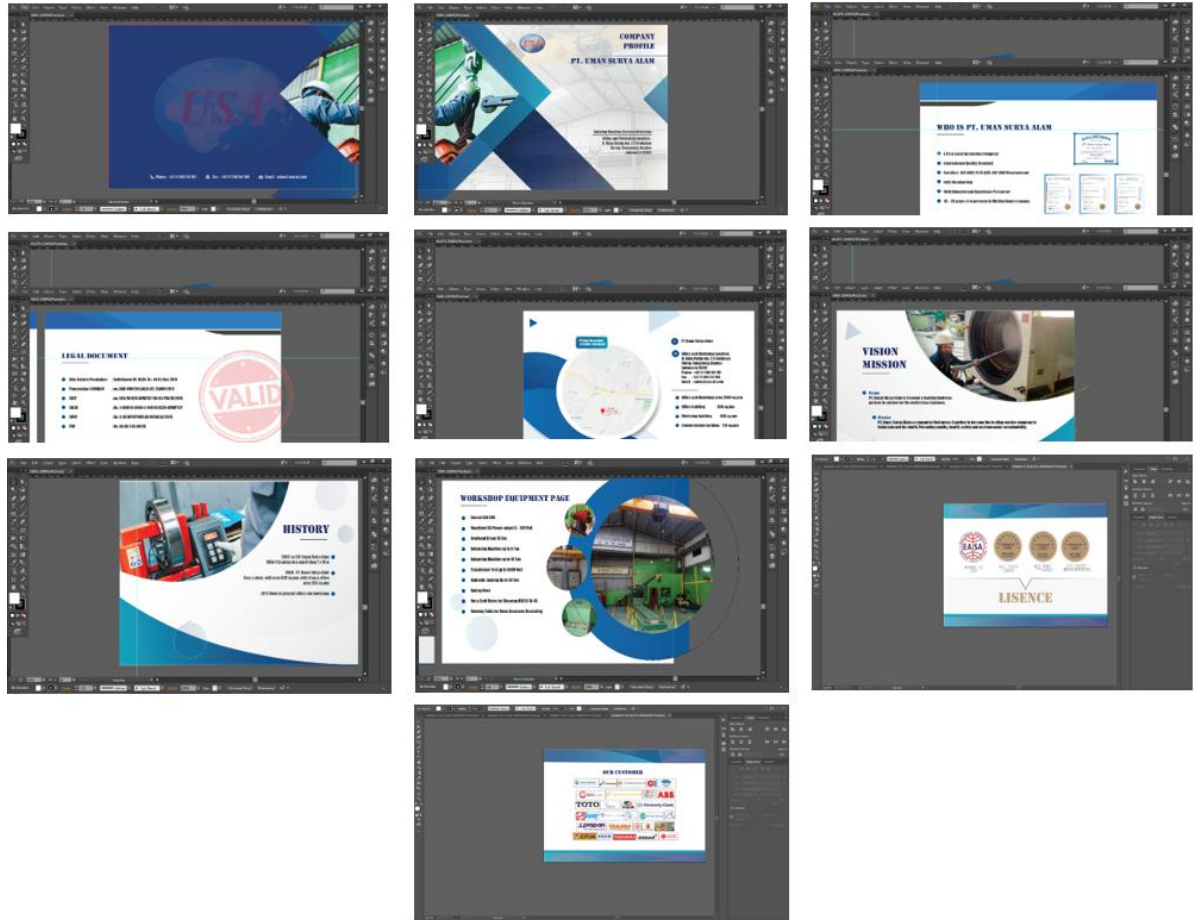

Gambar 12. Layout Komprehensif

\subsection{Final Artwork}

Final Artwork adalah tahap akhir sebagai bentuk penyelesaian dari layout kasar dan layout komprehensif untuk mendapatkan hasil desain yang siap dicetak. Berikut adalah final artwork desain majalah company profile yang telah dibuat:
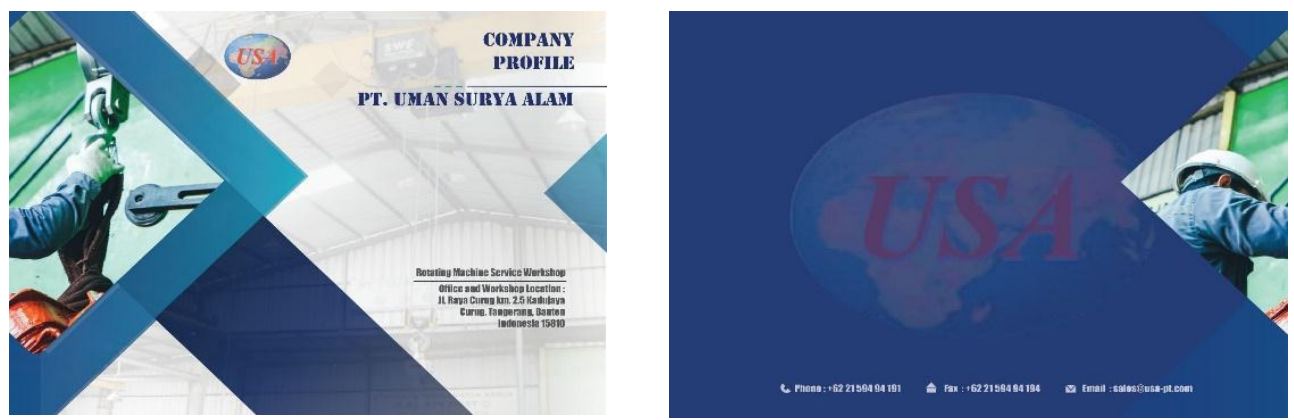

Gambar 13 dan 14. Final Artwork Cover dan Backcover

Pembuatan desain majalah bagian cover dan backcover ini bertujuan untuk menampilkan ilustrasi mengenai isi dari majalah, seperti judul majalah dengan nama perusahaan, logo dan informasi singkat perusahaan mulai dari alamat, email, dan nomor telepon yang bisa dihubungi. Untuk warnanya menggunakan perpaduan Putih dan Biru dengan efek gradasi. 


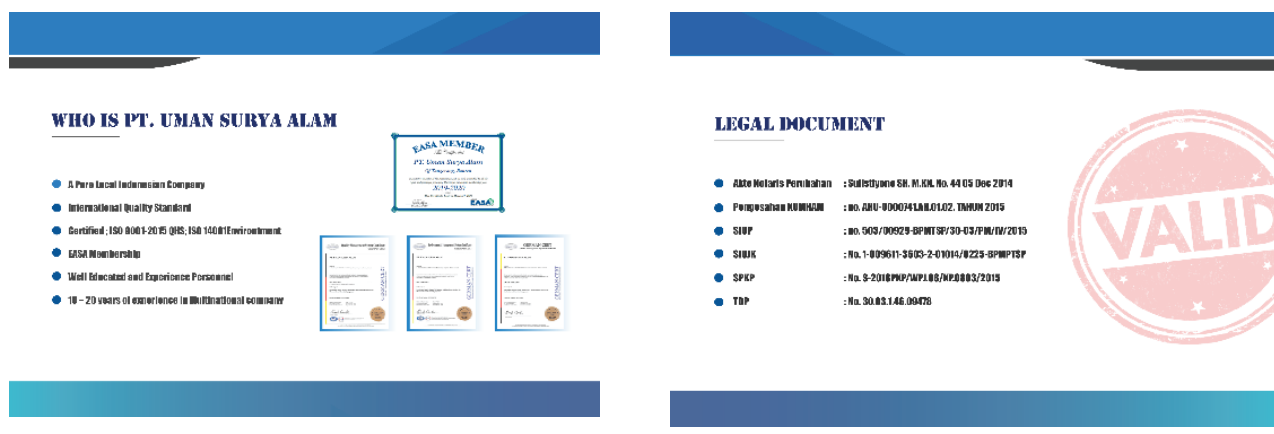

Gambar 15 dan 16. Final Artwork About Company dan Legal Document

Pada bagian ini menampilkan ilustrasi singkat tentang perusahaan yang memiliki standar kualitas internasional, bersertifikat; ISO 9001-2015 QHS; ISO 1400, bukti keanggotaan EASA (Electrical Apparatus Service Association) dan nomor dokumen legal yang dimiliki perusahaan. Desain ini menerapkan tema clean dan tidak terlalu banyak objek dengan dukungan warna biru dan putih dengan efek gradasi.
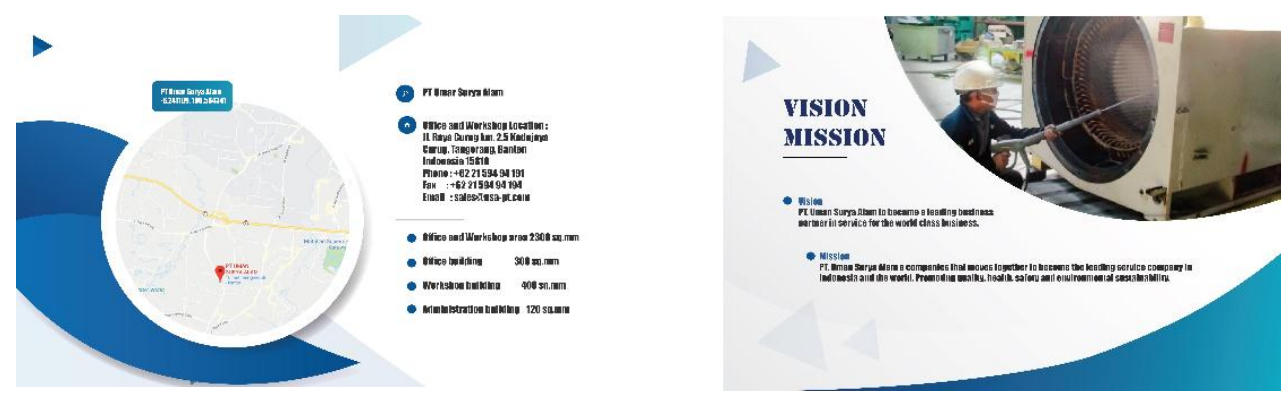

Gambar 17 dan 18. Final Artwork Company Address dan Vision Mision.

Pada bagian ini menampilkan ilustrasi mengenai letak geografis perusahaan dengan memperlihatkan alamat, tampilan lokasi menggunakan maps dan luas bangunan yang dimiliki. Terdapat visi dan misi perusahaan juga yang menjadi informasi paling pentingd ari desain majalah ini.
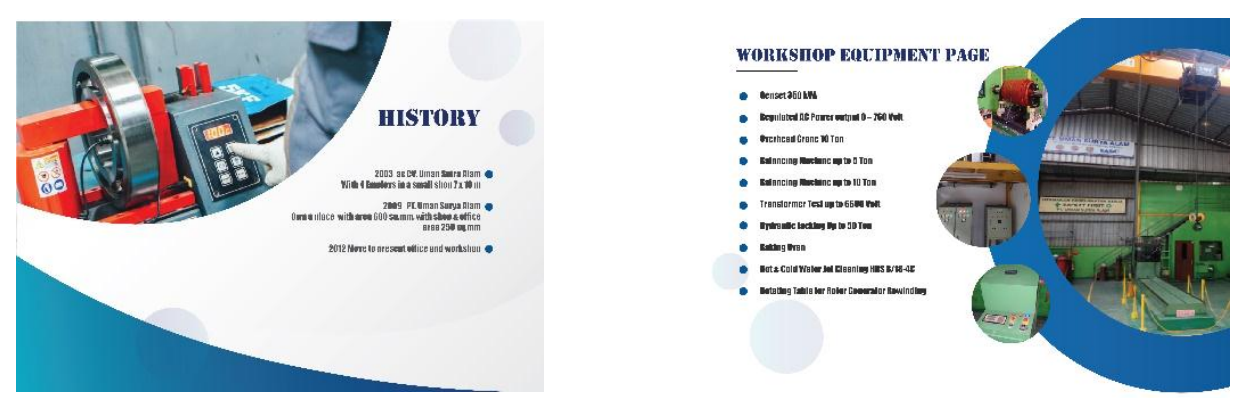

Gambar 19 dan 20. Final Artwork History dan Workshop Equipment.

Pada bagian ini menampilkan ilustrasi mengenai sejarah singkat perusahaan yang memperlihatkan awal perusahaan dibangun pada tahun 2003 yang masih berstatus CV Uman Sutra Alam hingga berubah menjadi PT Uman Surya Alam Pada tahun 2009 hingga pindah ke kantor dan memiliki bengkel pribadi pada tahun 2012 sampai sekarang. Sedangkan pada bagian workshop equipment memperlihatkan peralatan workshop yang 
dimiliki oleh PT Uman Surya Alam yang disertai dengan spesifikasinya untuk menunjang segala kebutuhan calon Customer dan klien. Terdapat gambar mesin yang dibentuk dalam lingkaran dengan perpaduan warna Biru dengan efek gradasi dan Putih.
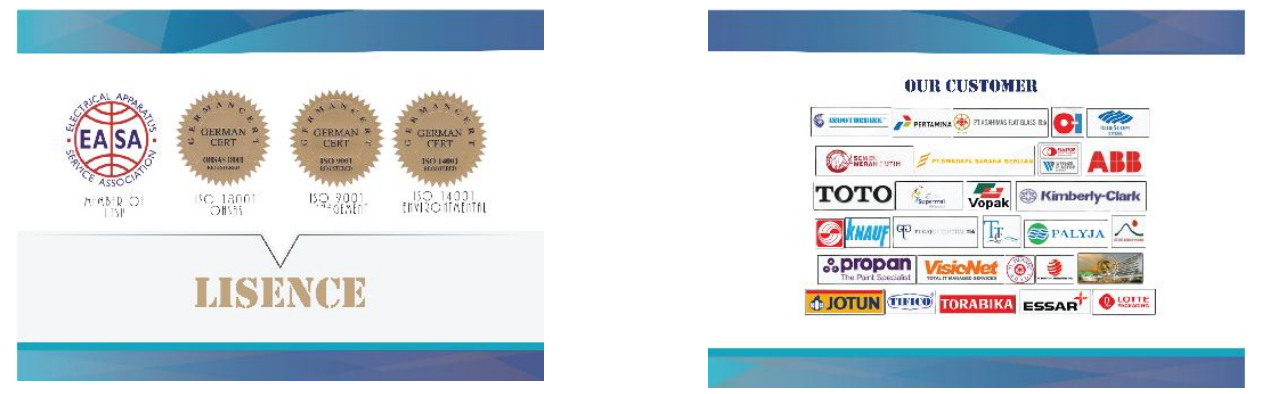

Gambar 21 dan 22. Final Artwork License dan Our Customer

Pada bagian ini menampilkan ilustrasi mengenai lisensi yang dimiliki oleh PT Uman Surya Alam sebagai perusahaan yang bergerak dalam bidang perbaikan dan perawatan mesin. Tidak hanya itu, majalah juga akan memperlihatkan beberapa customer yang telah bekerjasama dengan PT Uman Surya Alam.

\section{KESIMPULAN}

Sebagai media yang akan digunakan untuk Company Profile PT Uman Surya Alam, desain majalah yang dibuat sangat efektif dalam meningkatkan brand image produk atau perusahaan dimata masyarakat luas, khususnya kepada customer dalam menarik minat dan kepercayaannya, serta efesien dalam menjelaskan tentang perusahaan, secara detail dan lengkap serta didukung oleh gambar-gambar produk yang dikemas dalam tampilan visual majalah yang menarik. Sehingga dapat mempengaruh minat calon customer agar tertarik bekerjasama dengan perusahaan.

\section{SARAN}

Dengan dibuatkannya media desain company profile ini disarankan tidak hanya mengimplementasikannya ke dalam media cetak saja, tetapi mengimplementasikan juga ke dalam bentuk E-Magazine (majalah online) yang diletakan pada website perusahaan milik PT Uman Surya Alam dan juga terus mengembangkan media promosi dan informasi yang lebih menarik serta informatif kedepannya.

\section{DAFTAR PUSTAKA}

[1] Martono, D., Husain, A., dan Iswara, D. 2018. Media Company Profile Berbentuk Desain Booklet Menggunakan Aplikasi Photoshop CS5 di PT. Citra Surya Selaras Berbasis Multimedia. Tangerang: Journal SENSI. ISSN: 2655-5298. Vol.4, No.2.

[2] Muhammad, A., M., Prawiradiredja, S., dan Fitriyah, I. 2018. Corporate Value: Persona Pada Company Profile PT. Kereta Api Indonesia. Surabaya: Jurnal Komunikasi Profesional. ISSN: 2579-9371. Vol.2, No.1.

[3] Andriyan, W., Sindiawati., dan Kurnia, G., P. 2020. Desain Komunikasi Visual Sebagai Media Informasi Pada Kelurahan Kebon Besar Kota Tangerang. Jawa Barat: Bina Insani ICT Journal. ISSN: 2527-9777. Vol.7, No.1. 
[4] Maryanti, I., F., Gummah., Syifaul., dan Sukroyanti, B., A. 2018. Pengembangan Bahan Ajar Berbasis Majalah Siswa Pintar Fisika (MSPF) Untuk Meningkatkan Hasil Belajar Siswa. Mataram: Jurnal Ilmiah IKIP Mataram. ISSN: 2355-6358. Vol.5, No.1.

[5] Putri, Eka Citra., dan Radja Erland Hamzah. 2018. Konvergensi Konten Majalah Popular dalam Industri Digital Media Cetak. Jakarta: Jurnal Warta ISKI. ISSN: 26860724. Vol.1, No.2.

[6] Maulani, Giandari., Siti Nur Janah., dan Yuri Alam Mahbubi. 2017. Desain Media Komunikasi Visual Berbentuk Tabloid Sebagai Sarana Promosi SMK Mandiri 2. Pontianak: Jurnal Sisfotenika. ISSN: 2460-5344, Vol.7, No.1.

[7] Widada, Sugeng., Gustina., dan Vina Vijaya Kusuma. 2020. Perancangan Media Promosi dan Informasi Berbentuk Desain Majalah Pada SMK Ki Hajar Dewantoro. Tangerang:Universitas Raharja. MAVIB Journal. ISSN: 2723-200X. Vol.1, No.2.

[8] Kusuma, Vina Vijaya., M Ifran Sanni., dan Rifqi Irfan Maulana S. 2020. Desain Majalah Guna Media Penunjang Informasi Pada PT. Pramesta Baja Utama. Tangerang: Universitas Raharja. MAVIB Journal. ISSN: 2723-200X. Vol.1, No.1.

[9] Apriani, Desy., Khaerul Saleh., dan Allex Sandra Willyan. 2020. Desain Majalah Berbentuk Informasi dan Promosi Pada PT. Prabayksa Surya Albantani Kabupaten Tangerang. Tangerang: Universitas Raharja. MAVIB Journal. ISSN: 2723-200X. Vol.1. No.1 